\section{Elizabeth Leonard}

Correspondence concerning this column should be addressed to: Elizabeth Leonard, Assistant Dean of Information Technologies and Collection Services at Seton Hall University; e-mail:RUSQCareerConvo@gmail.com.
I n my experience, librarians believe they try very hard to be aware and supportive of people with differing abilities, both physical and intellectual. Our successes in this area tend to be public facing, with detailed attention paid to construction of public spaces, design of accessible online content, and creation of inclusive public programming. We talk about library services and outreach to people with disabilities - the web pages, articles, and blog posts out there are legion. Yet when it comes time to make hiring changes within our ranks, inclusivity doesn't happen. While I genuinely believe we want to support diversity in hiring, we fall short.

Discussing differently-abled people in the workplace is a challenging conversation, not because there's a difference of opinion on whether people with disabilities (PWD) should be hired, but more because the concept of disability is so complex. PWD span the spectrum of physical and intellectual differences. When talking about hiring PWD, you often need to clarify what are you attempting to do. Do you intend to hire someone with a learning difference? Someone with an intellectual capacity outside what you might generally see in a library? A physical difference? It is both impossible and insulting to cherry pick advocacy for one type or another. And I think we, as librarians, may be so worried that we will "do it wrong"-either in hiring or as team members-that we choose not to hire PWD at all.

I've written several versions of this but realized, as I was advised by a fellow author in this field, it is too difficult to reduce the conversation to the word count of this column. Instead, I am going to point you to some materials which can help you advocate for the hiring of PWD, as well as learn to recognize unintentional (and perhaps intentional) biases. This list is short; it isn't meant to be exhaustive. But these articles can help you on the path to improving the diversity of your library staff.

There are clear benefits to hiring PWD: Lindsay, Cagliostro, Albarico, Mortaji, and Karon reviewed 6,176 studies between 1997 and 2017 to ascertain the benefits of hiring PWD in a competitive employment environment. ${ }^{1}$ The study broke down benefits into two categories: those for the company and those for the PWD. The benefits for the company include reduced turnover and the associated lower costs of recruitment, hiring, and training. There is also the associated benefit of a more positive work culture and better competitive advantage.

While many of us are open to hiring PWD, fewer actually do so. Ameri et al. ran a field experiment wherein over 6,000 applications were sent to various job advertisements at 
two levels (entry level and experienced) using three different application profiles: a cover letter that disclosed a physical disability, a cover letter that disclosed an Asperger's diagnosis, and a cover letter that mentioned no disability. The authors found that the applications mentioning disability received 26 percent less interest than the control (nondisabled) applications, with a bigger gap noted for the more experienced candidates. ${ }^{2}$

Araten-Bergman, one of the more prolific authors in disability research, researched the gap between hiring managers intentions to hire PWD and actual hires of PWD. The author found that managers stated they wanted to hire PWD but generally failed to follow through on their stated intentions. Rather, the author found better correlations between companies having policies and internal support for hiring disabled people, including training, and actual hiring of PWD. ${ }^{3}$

For a meta-analysis on improving the hiring of PWD, see Gewurtz, Langan, and Shand. The authors selected fiftythree articles that were directly related to the processes for hiring PWD. They discuss issues around the hiring of PWD, including stigma, disclosure of disabilities, the surrounding legislation, and accommodations, as well as relationships between disability organizations and companies, support for the employers themselves, and specific hiring practices that can support hiring PWD. ${ }^{4}$

Concerned about implicit bias? So is Lucy Leske, author of "How Search Committees Can See Bias in Themselves." This practical review of some of the ways search committees unintentionally avoid hiring diverse candidates discusses the types of bias the committee might run into and then discusses ways the committee can actively work to overcome these unconscious or overt biases.

Jennifer Vinopal's call to action, "The Quest for Diversity in Libraries," is not specifically about disabilities but should not be skipped. ${ }^{6}$ The author explores the lack of diversity in our profession and discusses issues that exacerbate it, including more diverse individuals leaving library careers. The article then seeks to explain the underlying reasons libraries are not diverse, including the societal and environmental structures that must be addressed and removed to fully realize a diverse society.

From the author's clarion call to hire more PWD to an investigation into the experiences of librarians with disabilities, there's no greater current advocate for PWD in libraries than Joanne Oud. ${ }^{7}$ For a thorough review of global studies related to disability in libraries, read her most recent publication in College \& Research Libraries. ${ }^{8}$ Although the author's stated goal was to learn more about academic librarians with disabilities in Canada, Oud reviews articles from authors around the world. (The bibliography is an exhaustive exploration of the topic.) The author found that, while the experiences of those she interviewed were generally positive, librarians with disabilities did experience barriers and challenges in the workplace. The comments relating to the individual's self-perception of the positivity of disability were particularly interesting, especially those related to the open-mindedness and sensitivity of this population of librarians.

\section{TAKEAWAYS}

From a library perspective, we provide a public benefit to our patrons by modeling positive values of inclusivity. So, when I and others advocate for greater hiring of PWD, what are we saying? Hire more people with physical disabilities? Hire people with intellectual disabilities? My answer is, "yes." Our libraries should reflect our communities and provide opportunities, not limit them.

Research has shown that the best way to improve hiring of PWD is to create a written disability hiring policy and offering disability awareness training. ${ }^{9}$ Encourage your library and the wider organizations to engage in diversitypositive practices, such as disability training and including disabilities in the organization's diversity policy. Even if you can't afford expensive training opportunities, there are often low-cost or free options through state or regional organizations; search "cultural competence" and your state name. Additionally, the ALA has resources to support diversity in hiring: http://www.ala.org/advocacy/diversity/workforcede velopment/recruitmentfordiversity.

Finally, advocate for improvements to the tools librarians use. There are so many ways in which we can improve the work experience for our differently abled colleagues. For example, if a journal's submission guidelines might require the use of a serif font (for example, Times New Roman), which is more difficult for dyslexics to read. Do these requirements limit publication opportunities for people with dyslexia? Impossible to know but worth considering. We should consider reviewing and making changes to industry workflows and procedures that can unintentionally limit access to those of differing abilities. I recently attended a conference session on the accessibility of a library content management system, and an attendee with a visual disability requested that the vendor/developer pay as much attention to making the librarian design interface (the "back end") as accessible as the "front end" public-facing pages. Ask your vendors and others about the accessibility of the administrative side of online tools and advocate for those tools to be screen reader friendly. Our vendors' development roadmaps are generally led by our requests. Don't be afraid to use your voice to advocate for your fellow librarians.

Finally, remember a true path to diversity starts in the hiring process. Research shows that when differently abled students leave school and seek jobs, they face greater difficulties than their peers in finding work. ${ }^{10}$ Librarians have suggested that the library field is no different. ${ }^{11}$ As Leske suggests, have a discussion at the beginning of any hiring process about bias, both overt and implied. ${ }^{12}$ Get it out in the open so it can be overcome.

Help others get a hand up; doing so won’t pull you down. 


\section{CAREER CONVERSATIONS}

\section{References}

1. Sally Lindsay et al., "A Systematic Review of the Benefits of Hiring People with Disabilities," Journal of Occupational Rehabilitation 28, no. 4 (December 2018): 634-55, https://doi .org/10.1007/s10926-018-9756-z.

2. Mason Ameri, Lisa Schur, Meera Adya, F. Scott Bentley, Patrick McKay, and Douglas Kruse, "The Disability Employment Puzzle: A Field Experiment on Employer Hiring Behavior," ILR Review 71, no. 2 (March 2018): 329-64, https://doi .org/10.1177/0019793917717474.

3. Tal Araten-Bergman, "Managers' Hiring Intentions and the Actual Hiring of Qualified Workers with Disabilities," International Journal of Human Resource Management 27, no. 14 (July 15, 2016): 1510-30, https://doi.org/10.1080/09585192.2015.1 128466

4. Rebecca E. Gewurtz, Samantha Langan, and Danielle Shand, "Hiring People with Disabilities: A Scoping Review," Work 54, no. 1 (May 2016): 135-48, https://doi.org/10.3233/WOR $-162265$.

5. Lucy A. Leske, "How Search Committees Can See Bias in Themselves," The Chronicle of Higher Education, December 01, 2016, https://www.chronicle.com/article/How-Search-Committees -Can-See/238532.
6. Jennifer Vinopal, "The Quest for Diversity in Library Staffing: From Awareness to Action," In the Library with the Lead Pipe, January 13, 2016, http://www.inthelibrarywiththeleadpipe .org/2016/quest-for-diversity.

7. Joanne Oud, "Disability and Equity," American Libraries, January 2, 2019, https://americanlibrariesmagazine.org/2019/01/02 /disability-and-equity; Joanne Oud, "Academic Librarians with Disabilities: Job Perceptions and Factors Influencing Positive Workplace Experiences," Partnership: The Canadian Journal of Library and Information Practice and Research 13, no. 1 (2018), https://doi.org/10.21083/partnership.v13il.4090.

8. Joanne Oud, "Systemic Workplace Barriers for Academic Librarians with Disabilities," College \& Research Libraries 80, no. 2 (March 2019): 169-94, https://doi.org/10.5860/crl.80.2.169.

9. Araten-Bergman, "Managers' Hiring Intentions and the Actual Hiring of Qualified Workers with Disabilities."

10. Mike Annett, "Framing Supervisor Intentions and Actions for Hiring Candidates with a Disability," The Journal of Business Diversity 18, no. 3 (November 2018): 9-19.

11. Jodi Johnstone, "Employment of Disabled Personas in the Academic Library Environment," Australian Library Journal 54, no. 2 (2005): 156-63, https://doi.org/10.1080/00049670.2005 10721743 .

12. Leske, "How Search Committees Can See Bias in Themselves." 